\title{
Evaluation of the Relationship between Transcutaneous Carbondioxide Monitorization and End-tidal Carbondioxide and Partial Carbondioxide Monitorization
}

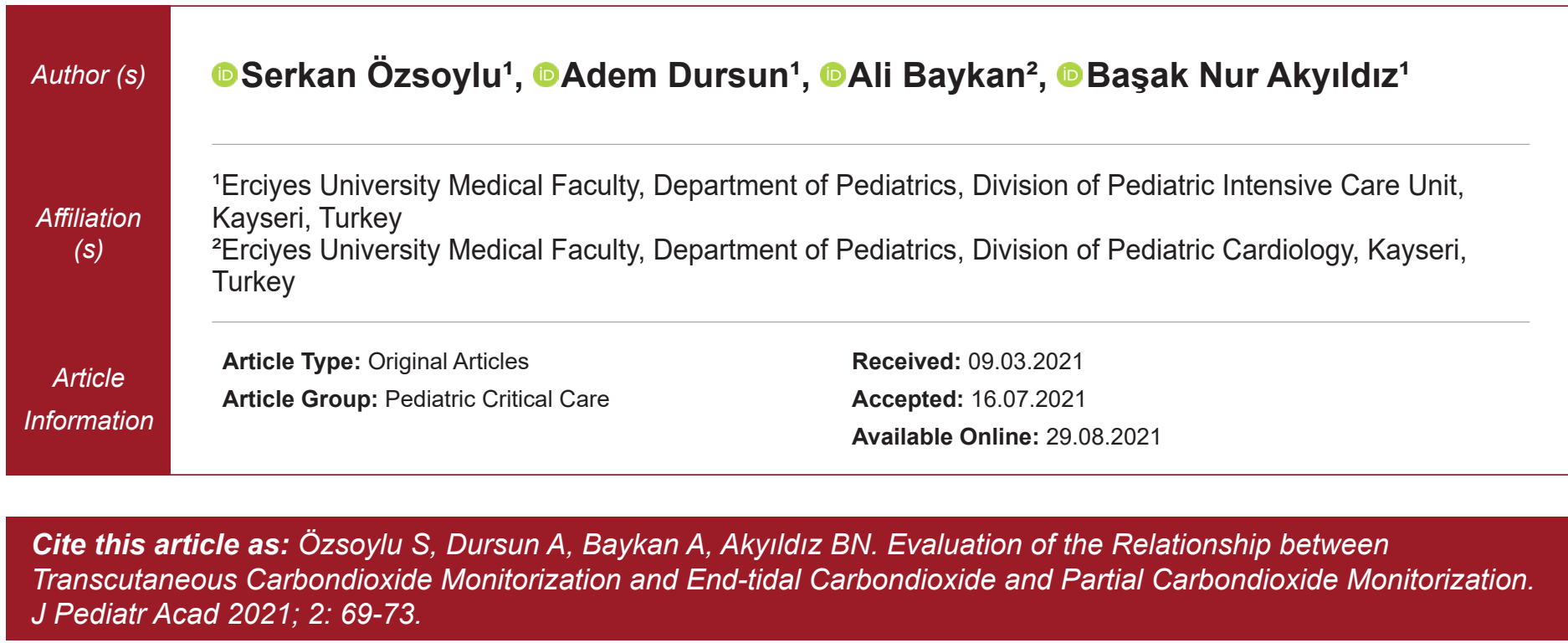

\section{Abstract}

Non-invasive methods have replaced invasive methods in line with developments in pediatric intensive care units. (Especially methods that enable continuous monitoring) Although arterial carbon dioxide measurement is still the gold standard for the evaluation of alveolar ventilation, the need for continuous monitoring of $\mathrm{PaCO}_{2}$ and the invasive nature of this method have led to the investigation of alternative methods. To evaluate the correlation of transcutaneous $\mathrm{CO}_{2}\left(\mathrm{TcCO}_{2}\right)$ monitoring with $\mathrm{PaCO}_{2}$ and $\mathrm{ETCO}_{2}$ in mechanically ventilated patients in peditaric intensive care units. Single-center, prospective, observational cohort study. We enrolled 60 patients between the age of 1 month-18 years who were mechanically ventilated in pediatric intensive care unit for this singlecenter, prospective, observational cohort study from February 2019 through March 2019. Correlation analysis was performed for arterial $\mathrm{PaCO}_{2}$, end-tidal $\mathrm{CO}_{2}, \mathrm{TcCO}_{2}$ parameters. $\mathrm{P}<0.05$ values were considered significant. The Bland-Altman plot was created for determining the agreement between the methods. The correlation of transcutaneous $\mathrm{CO}_{2}$ and end-tidal $\mathrm{CO}_{2}$ with arterial $\mathrm{PaCO}_{2}$ was evaluated, both parameters were found to be positively and highly correlated $(r=0.864, p<0.001, r: 0.962, p<0.001$, respectively). The mean bias between the arterial carbondioxide mesaurement and transcutaneous measurement was 5.5, and limits of agreement (bias $\pm 1.96 \mathrm{SD}$ ) ranged from -13.9 to 2.9 . The mean bias between the arterial carbondioxide mesaurement and endtidal carbondioxide measurement was 2.3 , and limits of agreement (bias $\pm 1.96 \mathrm{SD}$ ) ranged from -4.1 to 8.6 . In 44 measurements (88\%), the $\mathrm{TcCO}_{2}$ was $\pm 7.5 \mathrm{~mm} \mathrm{Hg}$ of the $\mathrm{PaCO}_{2}$. $\mathrm{TcCO}_{2}$ seems to be a good alternative for carbon dioxide measurement, as it is non-invasive and allows continuous monitoring in view of today's intensive care conditions, but arterial $\mathrm{PaCO}_{2}$ measurement is still the gold standard method. Continuous $\mathrm{TcCO}_{2}$ monitoring provides a promising alternative to repeated blood sampling in subjects requiring mechanical ventilation for critically ill children.

Keywords: Transcutaneous, carbondioxide, pediatric intensive care

Correspondence: Serkan Özsoylu, Erciyes University Medical Faculty, Department of Pediatrics,

Division of Pediatric Intensive Care Unit, Kayseri, Turkey

E-mail: sozsoylu@hotmail.com 


\section{Introduction}

In recent years, non-invasive methods have replaced invasive methods in line with developments in pediatric intensive care units. (Especially methods that enable continuous monitoring) Although arterial carbon dioxide measurement is still the gold standard for the evaluation of alveolar ventilation, the need for continuous monitoring of $\mathrm{PaCO}_{2}$ and the invasive nature of this method have led to the investigation of alternative methods. Therefore, transcutaneous $\mathrm{CO}_{2}\left(\mathrm{TcCO}_{2}\right)$ measurement, which is a painless procedure and allows continuous monitoring, is used in intensive care units with increasing frequency., ${ }^{1,2}$ Many studies have also shown that $\mathrm{TcCO}_{2}$ measurement is a good alternative to arterial $\mathrm{CO}_{2}$ measurement. ${ }^{1-5}$

End-tidal $\mathrm{CO}_{2} \quad\left(\mathrm{ETCO}_{2}\right)$ monitoring has been known, heretofore, as a useful tool to follow carbondioxide levels in mechanically ventilated patients. However, several factors affect $\mathrm{ETCO}_{2}$, such as pulmonary edema, obstruction of the airway and low cardiac output which are often found in critically ill patients in peditaric intensive care units.

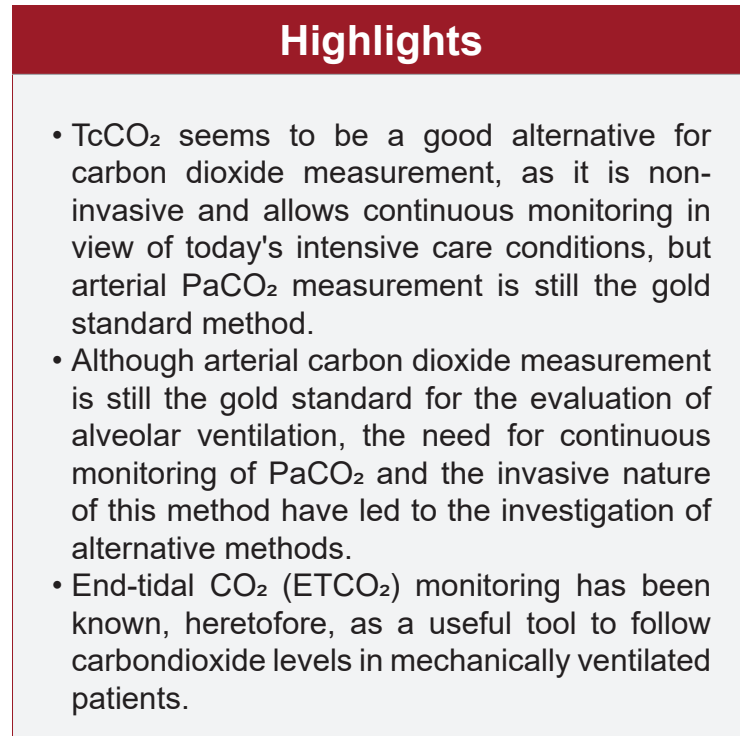

intensive care unit for this single-center, prospective, observational cohort study from 1 February 2019-31 March 2019. The exclusion criterias were: Hypotension, using inotropic agent, skin condition that does not allow probe to settle. This study was approved by Clinical Research Ethics Committee of Erciyes Universtiy Hospital (Date: 09.02.2018, Decision No: 2018/78). Informed consent was obtained from the parents of the patients.

\section{Data collection and procedures}

$\mathrm{PaCO}_{2}$, end-tidal $\mathrm{CO}_{2}$ and $\mathrm{TcCO}_{2}$ were measured simultaneously and correlation between these measurements were investigated. $\mathrm{PaCO}_{2}$, end-tidal $\mathrm{CO}_{2}$ and $\mathrm{TCCO}_{2}$ were measured 4 times from all the patients.

$\mathrm{PaCO}_{2}$ : Arterial blood sample is taken from the patients which we follow in intensive care and measured with RAPIDLAB 1265 brand blood gas device in our unit.

End-tidal $\mathrm{CO}_{2}$ : End-tidal $\mathrm{CO}_{2}$ measurement was performed by micro-side stream method (Capnostream $\left.{ }^{\circledR} 20 p / C o v i d i e n\right)$ in patients who were mechanically ventilated in intensive care.

Transcutaneous gas exchange monitors measure $\mathrm{PaO}_{2}$ and $\mathrm{PaCO}_{2}$ on the skin surface to estimate arterial carbon dioxide and oxygen pressure. These monitors provide local warming of the skin. Heat from the sensor expands the capillaries and increases local blood flow. Transcutaneous $\mathrm{CO}_{2}$ monitors measure $\mathrm{PaCO}_{2}$ emitted throughout the skin by the application of a sensor heated $38^{\circ} \mathrm{C}$ above body temperature (typically between $40^{\circ} \mathrm{C}$ and $44^{\circ} \mathrm{C}$ ) to ensure arterialization in the area where the probe is connected. So transcutaneous $\mathrm{CO}_{2}$ pressure and oxygen saturation are electrochemically measured by the sensor. It should not be forgotten that the deterioration of the patient's ventilation status may result in false positive or false negative results, and this should not be allowed to lead to delay or inaccuracy in the orientation of the patient's treatment. In addition to studies showing good and high compatibility between transcutaneous and arterial blood gas values, studies have also been published that have low compatibility. ${ }^{6-8}$ This controversy could be explained by the severity and the heterogenity of the diagnosis.

In this study, it was planned to evaluate the correlation of transcutaneous $\mathrm{CO}_{2}\left(\mathrm{TcCO}_{2}\right)$ monitoring with $\mathrm{PaCO}_{2}$ and $\mathrm{ETCO}_{2}$ in mechanically ventilated patients in peditaric intensive care units.

\section{Material and Method}

\section{Study design}

We enrolled 60 patients between the age of 1 month-18 years who were mechanically ventilated in pediatric
Capno-oxymetry: $\mathrm{TcCO}_{2}$ levels were measured with the help of a probe (V-Sign $\left.{ }^{\mathrm{TM}} \mathrm{VS}-\mathrm{A} / \mathrm{P}\right)$ and a device (SenTec digital Monitor System).

\section{Statistical Analysis}

In G-power 3.1.9.2 programme, efect size 0.25 type 1 error was received as $5 \%$, power as $80 \%$. According to this, the number of samples to be taken was calculated as 43 . The study was planned to be conducted with 50 patients considering $10 \%$ data loss. All statistical analyses were performed using SPSS 22.0 (SPSS Inc., Chicago, IL, ABD) and MedCalc 13.3 (MedCalc Software Inc., Mariakerke, Belgium), with the statistical significance set at $p<0.05$. Frequency distributions were evaluated as number and percentage, continuous variables (measurements) were evaluated as mean \pm standard deviation. The distribution of the data (normal or not) was determined by performing a Shapiro Wilk test. Pearson correlation analysis was performed for arterial $\mathrm{PaCO}_{2}$, end-tidal $\mathrm{CO}_{2}, \mathrm{TcCO}_{2}$ parameters. $p<0.05$ values were considered significant. The BlandAltman plot was created for determining the agreement between the methods. Bias was calculated as the main difference between both methods and limits of agreement as the range in which $95 \%$ of the differences between 2 methods are expected to lie..$^{9}$ An additional analysis was performed to calculate the percentage of data in the bias range, with the measurement percentage range being $\pm 7.5 \mathrm{mmHg}$ because the clinically acceptable agreement between $\mathrm{TcCO}_{2}$ and $\mathrm{PaCO}_{2}$ is $\pm 7.5 \mathrm{mmHg} .{ }^{10}$ 


\section{Results}

A total of 60 patients who were admitted to the Pediatric Intensive Care Unit between 1 month and 18 years of age were included in the study. 10 patients who had measurement problems and impossible optimal monitoring were excluded from the study. Of the patients who participated in the study, 26 were boys (52\%) and $24(48 \%)$ were girls. The median age of the patients was 14 months. (min: 2-max: 168) According to the admission diagnoses of the patients, $6(12 \%)$ patients due to respiratory, $10(20 \%)$ patients due to neurological problems, $16(32 \%)$ patients due to cardiac problems, $6(12 \%)$ patients due to renal failure, and $12(24 \%)$ patients due to endocrinological problems were admitted to intensive care (Table 1).

\section{Table 1}

Characteristics of study subjects

\begin{tabular}{lc}
\hline Characteristics & Values \\
\hline Age, mean \pm SD (month) & $14 \pm 11.3$ \\
Male, sex $n(\%)$ & $26(52)$ \\
Body weight (min-max) & $13.7(10.2-35)$ \\
BMI (min-max) & $24.7(18.4-31.2)$ \\
Body Temperature oC (min-max) & $36.6(36.1-37.2)$ \\
Diagnosis at the admission $\mathbf{n}(\%)$ & \\
Respiratory problems & $6(12 \%)$ \\
Neurological problems & $10(20 \%)$ \\
Cardiac problems & $16(32 \%)$ \\
Renal problems & $6(12 \%)$ \\
Endocrinological problems & $12(24 \%)$ \\
Blood gases, mean $\pm S D$ & \\
pH & $7.32 \pm 0.9$ \\
PaCO 2, mmHg & $51 \pm 3.7$ \\
TcCO 2, mmHg & $45.1 \pm 4.2$
\end{tabular}

When the correlation of transcutaneous $\mathrm{CO}_{2}$ and end-tidal $\mathrm{CO}_{2}$ with arterial $\mathrm{PaCO}_{2}$ was evaluated, both parameters were found to be positively and highly correlated $(r=0.864, p<0.001, r: 0.962, p<0.001$, respectively) (Figure 1,2).

The median $\mathrm{PaCO}_{2}$ was $41 \mathrm{mmHg}$ (IQR 35-51 mmHg), with a range $21-76 \mathrm{mmHg}$. The median $\mathrm{PTcCO}_{2}$ was $43 \mathrm{mmHg}$ (IQR 32-49 $\mathrm{mmHg}$ ) with a range of 27-74 $\mathrm{mmHg}$. The median end-tidal $\mathrm{CO}_{2}$ was $38 \mathrm{mmHg}$ (IQR 28-47 $\mathrm{mmHg}$ ), with a range $18-66 \mathrm{mmHg}$.

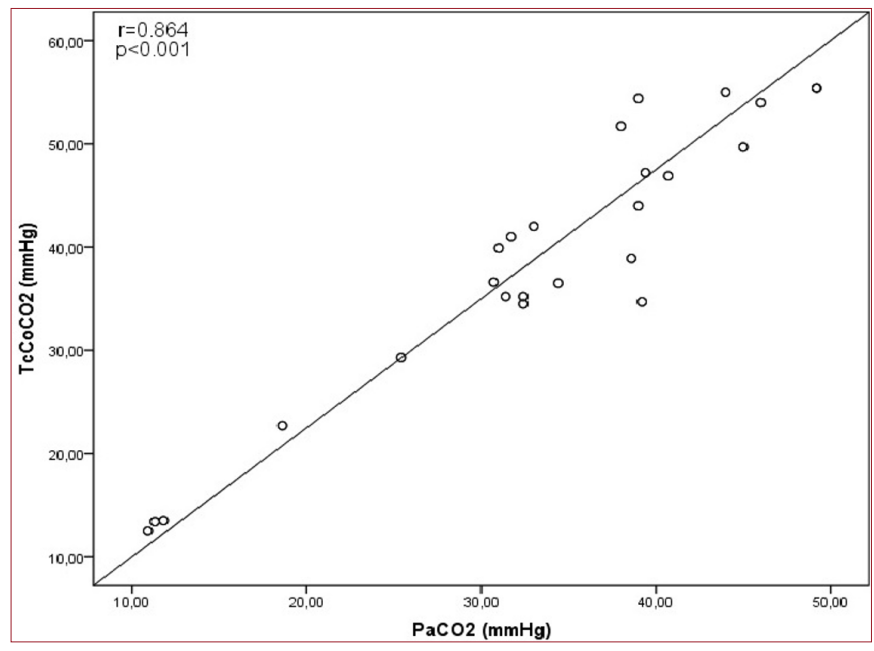

Figure 1. Correlation graphic between $\mathrm{PaCO}_{2}$ and $\mathrm{TcCO}_{2}$

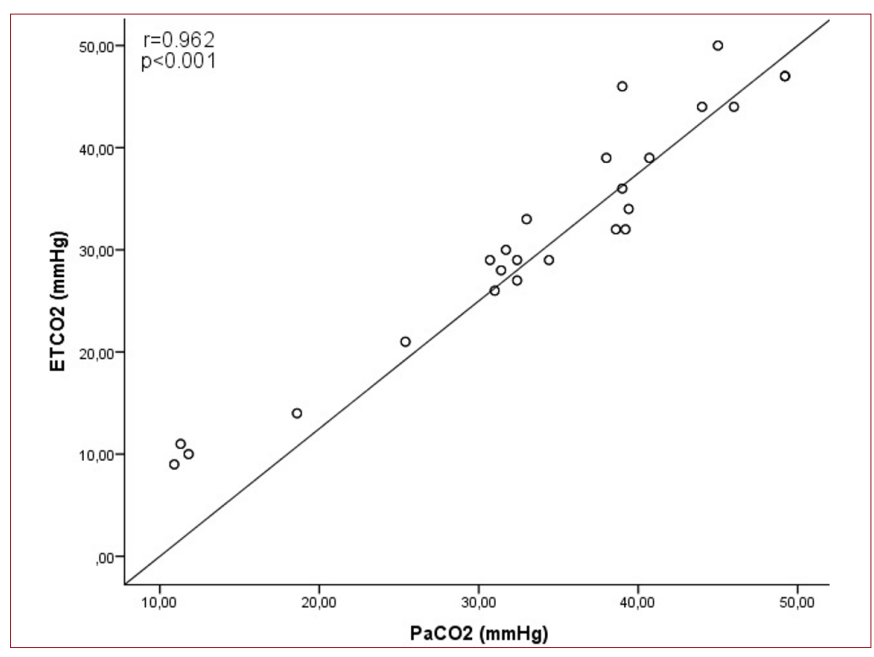

Figure 2. Correlation graphic between $\mathrm{PaCO}_{2}$ and $\mathrm{ETCO}_{2}$

The mean bias between the arterial carbondioxide mesaurement and transcutaneous measurement was 5.5 , and limits of agreement (bias $\pm 1.96 \mathrm{SD}$ ) ranged from -13.9 to 2.9. (Figure 3 ) The mean bias between the arterial carbondioxide mesaurement and end-tidal carbondioxide measurement was 2.3, and limits of agreement (bias \pm 1.96 $\mathrm{SD}$ ) ranged from -4.1 to 8.6 . (Figure 4 ) In 44 measurements $(88 \%)$, the $\mathrm{TcCO}_{2}$ was $\pm 7.5 \mathrm{mmHg}$ of the $\mathrm{PaCO}_{2}$.

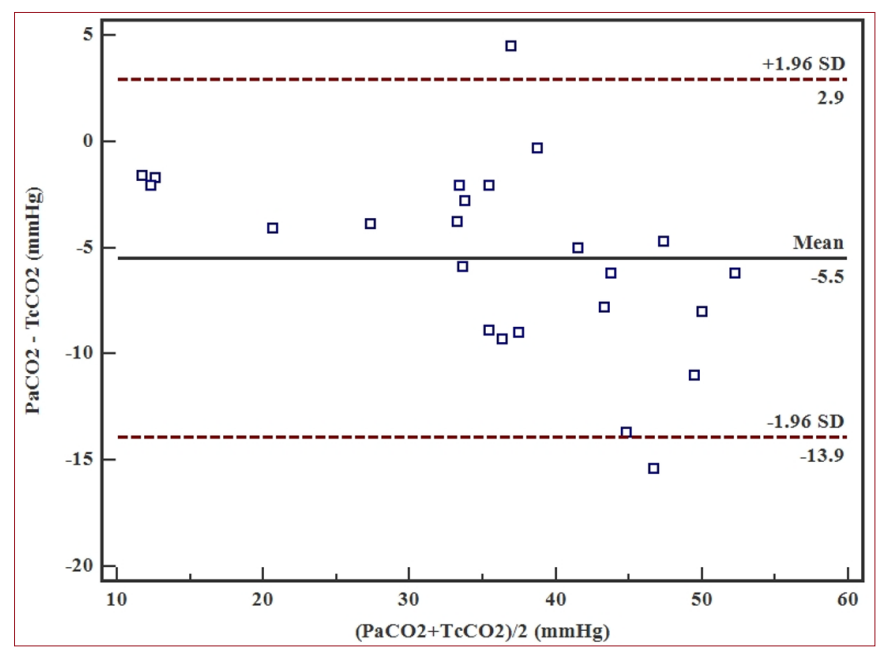

Figure 3. Blant-altman analysis for $\mathrm{TcCO}_{2}$ versus $\mathrm{PaCO}_{2}$. Bias (continous line), limits of agrement (bias \pm 1.96 , dashed lines) are shown in graph. Each square indicates the bias the bias of a single patient.

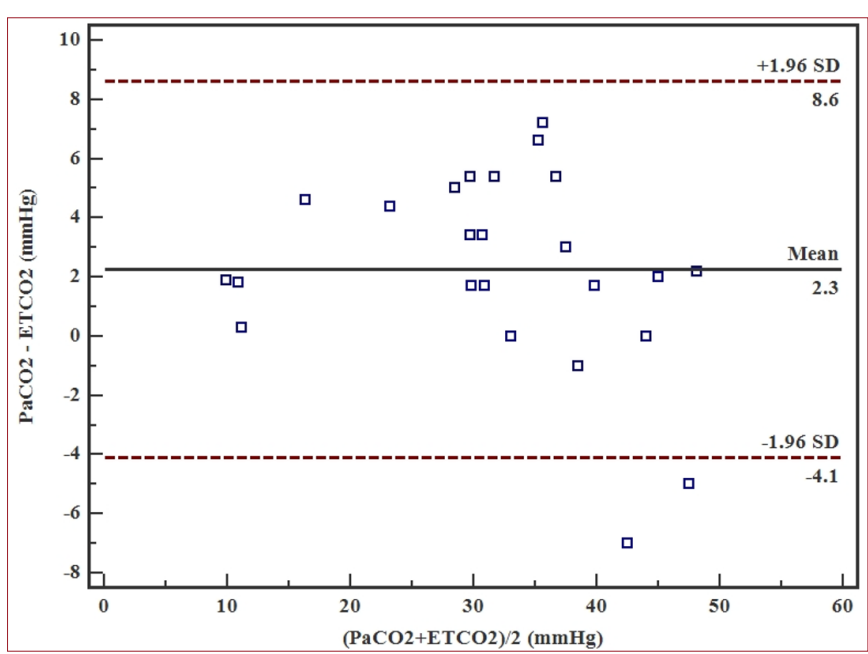

Figure 4. Blant-altman analysis for $\mathrm{ETCO}_{2}$ versus $\mathrm{PaCO}_{2}$. Bias (continous line), limits of agrement (bias \pm 1.96 , dashed lines) are shown in graph. Each ssquare indicates the bias the bias of a single patient. 


\section{Discussion}

Arterial $\mathrm{PaCO}_{2}$ is still the gold standard for the evaluation of alveolar ventilation but the desirable method for estimating $\mathrm{PaCO}_{2}$ value in a critically ill child is the method that provides non-invasive, reliable and continuous monitoring. ${ }^{5}$ This is one of the most detailed studies comparing two different non-invasive techniques for continuous carbon dioxide measurement with arterial blood gas carbon dioxide measurement (the gold standard method of alveolar ventilation) in patients undergoing mechanical ventilaiton in a pediatric intensive care unit. The main finding of the present study is that $\mathrm{TcCO}_{2}$ monitoring is an appropriate method for continuously measuring $\mathrm{PCO}_{2}$ in ventilated patients. In critical patients receiving respiratory support, closely monitoring cardiorespiratory changes and instantly recognizing clinical worsening are very important for follow-up and treatment. Therefore, continuous monitoring of $\mathrm{CO}_{2}$ levels with $\mathrm{TcCO}_{2}$ has the potential to prevent many of the known problems associated with end-tidal $\mathrm{CO}_{2}$ monitorization in critically ill children.

There have been many studies in newborns, adults and children to demonstrate the relationship between $\mathrm{PaCO}_{2}$ and $\mathrm{TcCO}_{2}$, but there are still studies that show that there is correlation, as well as studies that suggest otherwise. ${ }^{11-17}$ In a study of patients admitted to the emergency department with respiratory problems, the mean difference between $\mathrm{PaCO}_{2}$ and $\mathrm{TcCO}_{2}$ was 1 $\mathrm{mmHg}$ with limits of agreement of -3.4 to 5.6 was found by Delerme et al. ${ }^{5}$ Perrin et al. ${ }^{18}$ found a bias of 0.13 $\mathrm{mmHg}$ with limits of agreement of -3.9 and $3.7 \mathrm{mmHg}$ in asthmatic patients. Different from previous studies, we found the mean bias between the arterial carbondioxide mesaurement and transcutaneous measurement was 5.5 , and limits of agreement (bias $\pm 1.96 \mathrm{SD}$ ) ranged from -13.9 to 2.9. We explain this worse results with the higher $\mathrm{PaCO}_{2}$ levels of our patients. While mean $\mathrm{PaCO}_{2}$ of our patients is $51 \mathrm{mmHg}$, mean $\mathrm{PaCO}_{2}$ of previous studies are respectively 39 and $36 \mathrm{mmHg}$. Our findings are consistent with the findings of other authors, who argue that the reliability and accuracy of this method decreases in patients with high levels of $\mathrm{PaCO}_{2}{ }^{2,19}$

In previous studies, the predicted range for $\mathrm{TcCO}_{2}$ was assumed to be $\pm 7.5 \mathrm{mmHg}$ and $81.2 \%$ of cases remained within this range. ${ }^{13}$ Another study by Anoopindar et al. ${ }^{20}$ found that $83.2 \%$ of cases remained within this range when the estimated range of $\pm 7.5 \mathrm{mmHg}$ was accepted. Our study also found that $88 \%$ of the cases were in this range consistent with the literature.

Anoopindar et al. $^{20}$ reported that they did not find a significant association between high lactate levels, high doses of inotropes (higher vasoactive inotrope scores) and $\mathrm{TcCO}_{2} 5 \mathrm{mmHg}$ higher than $\mathrm{PaCO}_{2}$. In previous studies, a decreased correlation between $\mathrm{PaCO}_{2}$ and $\mathrm{TcCO}_{2}$ was observed at epinephrine doses as high as $0.3 \mathrm{ug} / \mathrm{kg} / \mathrm{min} .{ }^{21}$ In our study, 5 of 12 patients with cardiac problems received such a high dose of inotrope, but we did not see this association in our subgroup. It is possible that most children with cardiac disease did not have low cardiac output at the time of measurement so they had enough cardiac output to ensure skin perfusion.
In a study on non-invasive carbon dioxide monitorization conducted by Tobias et al. ${ }^{21}$ regression analysis revealed an $r$ value of 0.9693 when comparing transcutaneous versus arterial $\mathrm{PaCO}_{2}$ values and an $r$ value of 0.8745 when comparing end-tidal versus arterial $\mathrm{CO}_{2}$. Consistent with these findings, in our study the correlation of transcutaneous $\mathrm{CO}_{2}$ and end-tidal $\mathrm{CO}_{2}$ with arterial $\mathrm{PaCO}_{2}$ were both found to be positively and highly correlated (R:0.864, $p<0.001, r: 0.962, p<0.001$, respectively).

There are some limitations in our study. The first was that our number of patients was small. The second was although higher temperatures increased the reliability of the $\mathrm{TcCO}_{2}$ measurement we use the V-Sign Sensor 2 (which heats up to $42^{\circ} \mathrm{C}$ ) probe to avoid injury and burns. The third was that due to the low number of patients with respiratory problems, we were unable to obtain clear data on the differences from alveolar dead space between endtidal $\mathrm{CO}_{2}$ and $\mathrm{PaCO}_{2} / \mathrm{TcCO}_{2}$. And also this is a singlecentre study and one type of sensor device was used.

\section{Conclusion}

As a result, $\mathrm{TcCO}_{2}$ seems to be a good alternative for carbon dioxide measurement, as it is non-invasive and allows continuous monitoring in view of today's intensive care conditions, but arterial $\mathrm{PaCO}_{2}$ measurement is still the gold standard method. This study shows that continuous $\mathrm{TcCO}_{2}$ monitoring provides a promising alternative to repeated blood sampling in subjects requiring mechanical ventilation for critically ill children. But further research is needed for the reliability of $\mathrm{TcCO}_{2}$ measurement especially in special patient groups (tissue perfusion impaired, severe ARDS, shock, etc.)

Author Contributions: All of the authors declare that they have all participated in the design, execution, and analysis of the paper, and that they have approved the final version.

Conflict of Interest: There are no conflicts of interest in connection with this paper, and the material described is not under publication or consideration for publication elsewhere.

Ethics Committee Approval: This study was approved by Clinical Research Ethics Committee of Erciyes Universtiy Hospital (Date: 09.02.2018, Decision No: 2018/78).

Financial Disclosure: This study was supported by the Scientific Research Projects Commission with the project code TSA-2018-8152.

Informed Consent: Informed consent was obtained from the parents of the patients.

\section{References}

1. Storre $\mathrm{JH}$, Magnet FS, Dreher M, Windisch W. Transcutaneous monitoring as a replacement for arterial $\mathrm{PCO}_{2}$ monitoring during nocturnal non-invasive ventilation. Respir Med. 2011;105:143-50. [CrossRef]

2. Storre JH, Steurer B, Kabitz HJ, Dreher M, Windisch W. Transcutaneous $\mathrm{PCO}_{2}$ monitoring during initiation of noninvasive ventilation. Chest. 2007;132:1810-6. [CrossRef] 
3. Mallat J, Vallet B. Mucosal and cutaneous capnometry for the assessment of tissue hypoperfusion. Minerva Anestesiol. 2018;84:68-80. [CrossRef]

4. Vallée $F$, Nougué $H$, Mari $A$, et al. Variations of Cutaneous Capnometry and Perfusion Index During a Heating Challenge is Early Impaired in Septic Shock and Related to Prognostic in NonSeptic Shock. Shock. 2019;51:585-92. [CrossRef]

5. Delerme S, Montout V, Goulet H, et al. Concordance between transcutaneous and arterial measurements of carbon dioxide in an ED. Am J Emerg Med. 2012;30:1872-6. [CrossRef]

6. Nishiyama T, Nakamura S, Yamashita K. Effects of the electrode temperature of a new monitor, TCM4, on the measurement of transcutaneous oxygen and carbon dioxide tension. J Anesth. 2006;20:331-4. [CrossRef]

7. Peschanski N, Garcia L, Delasalle E, et al. Can transcutaneous carbon dioxide pressure be a surrogate of blood gas samples for spontaneously breathing emergency patients? The ERNESTO experience. Emerg Med J. 2016;33:325-8. [CrossRef]

8. Ruiz Y, Farrero E, Córdoba A, González N, Dorca J, Prats E. Transcutaneous Carbon Dioxide Monitoring in Subjects With Acute Respiratory Failure and Severe Hypercapnia. Respir Care. 2016;61:428-33. [CrossRef]

9. Bland JM, Altman DG. Statistical methods for assessing agreement between two methods of clinical measurement. Lancet. 1986;1:307-10. [CrossRef]

10. Restrepo RD, Hirst KR, Wittnebel L, Wettstein R. AARC clinical practice guideline:transcutaneous monitoring of carbon dioxide and oxygen: 2012. Respir Care. 2012;57:1955-62. [CrossRef]

11. Bolliger D, Steiner LA, Kasper J, Aziz OA, Filipovic M, Seeberger MD. The accuracy of non-invasive carbon dioxide monitoring:a clinical evaluation of two transcutaneous systems. Anaesthesia. 2007;62:394-9. [CrossRef]
12. Berkenbosch JW, Tobias JD. Transcutaneous carbon dioxide monitoring during high-frequency oscillatory ventilation in infants and children. Crit Care Med. 2002;30:1024-7. [CrossRef]

13. Urbano J, Cruzado V, López-Herce J, del Castillo J, Bellón JM, Carrillo A. Accuracy of three transcutaneous carbon dioxide monitors in critically ill children. Pediatr Pulmonol. 2010;45:481-6. [CrossRef]

14. Tobias JD. Transcutaneous carbon dioxide monitoring in infants and children. Paediatr Anaesth. 2009;19:434-44. [CrossRef]

15. Chhajed PN, Miedinger D, Baty F, et al. Comparison of combined oximetry and cutaneous capnography using a digital sensor with arterial blood gas analysis. Scand J Clin Lab Invest. 2010;70:60-4 . [CrossRef]

16. Nicolini A, Ferrari MB. Evaluation of a transcutaneous carbon dioxide monitor in patients with acute respiratory failure. Ann Thorac Med. 2011;6:217-20. [CrossRef]

17. Johnson DC, Batool S, Dalbec R. Transcutaneous carbon dioxide pressure monitoring in a specialized weaning unit. Respir Care. 2008;53:1042-7. [CrossRef]

18. Perrin K, Wijesinghe M, Weatherall M, Beasley R. Assessing $\mathrm{PaCO}_{2}$ in acute respiratory disease:accuracy of a transcutaneous carbon dioxide device. Intern Med J. 2011;41:630-3. [CrossRef]

19. Cuvelier A, Grigoriu B, Molano LC, Muir JF. Limitations of transcutaneous carbon dioxide measurements for assessing longterm mechanical ventilation. Chest. 2005;127:1744-8. [CrossRef]

20. Bhalla AK, Khemani RG, Hotz JC, Morzov RP, Christopher JL. Accuracy of Transcutaneous Carbon Dioxide Levels in Comparison to Arterial Carbon Dioxide Levels in Critically III Children. Respir Care 2019;64:201-8. [CrossRef]

21. Tobias JD, Russo P, Russo J. An evaluation of acid-base changes following aortic cross-clamping using transcutaneous carbon dioxide monitoring. Pediatr Cardiol. 2006;27:585-8. [CrossRef] 